\title{
Techniques to reduce shoulder pain after laparoscopic surgery for benign gynaecological disease: a systematic review
}

\author{
Buket Taş • Anders Meller Donatsky • Ismail Gögenur
}

Received: 19 February 2013 / Accepted: 28 March 2013 /Published online: 27 April 2013

(C) Springer-Verlag Berlin Heidelberg 2013

\begin{abstract}
Due to the well-known advantages of minimal invasive surgery, the majority of procedures for benign gynaecological diseases are performed by laparoscopy. Although laparoscopic surgery results in improved patient satisfaction, a considerable portion of patients have complaints of post-operative shoulder pain. This review presents an overview of the currently evaluated techniques to reduce shoulder pain after laparoscopic surgery for benign gynaecological disease. According to the Preferred Reporting Items for Systematic Reviews and Meta-Analysis guidelines, a systematic review was conducted using Medline, Embase and Cochrane databases. Randomised clinical trials reporting techniques to reduce shoulder pain after laparoscopic gynaecologic procedures for benign diseases were included. Eighty-eight articles were screened for inclusion. A total of 15 articles were included in the final review. The following studies described the techniques used to reduce shoulder pain: six studies evaluated the effect of local anaesthetics, three studies evaluated the effect of pulmonary recruitment manoeuvre and three studies evaluated the effect of intraperitoneal drainage. The remaining three studies evaluated the effect of saline installation, minilaparoscopy and gasless laparoscopy by using the Laprolift ${ }^{\circledR}$. Overall, the pulmonary recruitment manoeuvre and intraperitoneal drainage were found to reduce the incidence and severity of shoulder
\end{abstract}

\section{B. Taş}

Erasmus Medical Centre Rotterdam, 's- Gravedijkwal 230,

3015 CE Rotterdam, The Netherlands

A. M. Donatsky · I. Gögenur

Department of Surgery, University Hospital of Copenhagen,

Herlev, Herlev Ringvej 75,

2730 Herlev, Denmark

B. Taș $(\bowtie)$

Verboomstraat 30,

3082 JN Rotterdam, The Netherlands

e-mail: bukettas@hotmail.com pain (SP). Based on the current evidence, safety and possibility to implement the technique in daily practice, pulmonary recruitment manoeuvre can be recommended to reduce both the incidence and severity of SP.

Keywords Laparoscopy · Gynaecology · Shoulder pain · Gynaecologic surgery

\section{Introduction}

Laparoscopic surgery in patients with benign gynaecological diseases has several advantages compared to open surgery such as faster recovery, reduced hospital stay, lower morbidity and better cosmetic results [1-4]. Although laparoscopic surgery results in improved patient satisfaction, a considerable portion of patients have complaints of post-operative shoulder pain (SP). Post-operative SP is hypothesised to be a result of pneumoperitoneum achieved by carbon dioxide insufflation which induces peritoneal stretching, irritation of the diaphragm and phrenic nerve resulting in referred pain to the shoulder [5]. The precise aetiology is not fully known.

The incidence of SP in the first post-operative day is 35 to $61 \%$ [6-8]. The severity ranges from mild to severe, and some patients even have SP for more than $72 \mathrm{~h}$ after surgery [9]. While the exact pathogenesis of post-operative SP is not fully understood, different techniques to reduce the incidence and severity of SP after benign gynaecological laparoscopy have been evaluated in the literature.

The aim of this study was to critically appraise the effectiveness of different techniques in reducing postoperative SP after laparoscopic surgery in terms of the incidence and/or severity of SP. If enough high-quality studies were retrieved and if a clinically relevant and statistically significant difference was demonstrated, we aimed to give a recommendation for daily practice. 


\section{Methods}

Search strategy

On the basis of the Preferred Reporting Items for Systematic Reviews and Meta-Analysis, a systematic review was conducted. The literature search was conducted by a clinical librarian in the Medline, Embase and Cochrane databases. All randomised controlled trials (RCTs) published in the English language were selected for screening based on the following search terms: "shoulder pain" and "gynecologic" and "laparoscopy". No restriction in the year of publication was applied. The exact search terms are demonstrated in the appendix wherein a combination of MeSH terms and free text words was applied.

\section{Study selection}

Two independent reviewers selected all relevant articles. First, the authors eliminated independently and simultaneously all duplicates and articles that were not relevant by looking at the titles and/or abstracts. Subsequently, the relevant articles were selected on the basis of reading the full text manuscripts. The eligibility criteria for inclusion were based on study design and outcome measurements. The outcome measurements include incidence of shoulder pain, severity of shoulder pain on any scale and the need for postoperative analgesics. For study design, only RCTs reporting techniques to reduce SP after benign laparoscopic gynaecologic procedures under general anaesthesia were included. For outcome measurements, only studies reporting the incidence and/or the severity of "shoulder pain" or "shoulder tip pain" were included. The severity of shoulder pain could be assessed on any scale.

The two reviewers identified the articles that met the eligibility criteria. The final inclusion of articles was based on reading the full article. If disagreement regarding inclusion occurred, an agreement was reached by discussion. Finally, to identify other relevant RCTs, a manual search was made in the reference lists of the reviewed papers.

\section{Data extraction}

The following data were extracted from the included RCTs: year of publication, total number of participants and respective allocation, laparoscopic procedure, intervention type, administration method and location for intraperitoneal solutions, significant and non-significant results on incidence and/or severity of SP measured on any scales at rest/cough/mobilisation and post-operative analgesic consumption. The data extracted are presented in tables for each intervention type.

\section{Results}

The search strategy identified 88 articles which were screened for inclusion. Fifteen RCTs were included in the final review. Reasons for exclusion are presented in the flow chart (Fig. 1). Of the included RCTs, six studies evaluated the effect of intraperitoneal local anaesthetics [10-15], three studies evaluated the effect of pulmonary recruitment manoeuvre (PRM) $[5,8,16]$ and three studies evaluated the effect of drainage [17-19]. The remaining three studies have been grouped together as "other techniques" and evaluated the effect of intraperitoneal saline installation [20], minilaparoscopy [21] and gasless laparoscopy by using Laprolift ${ }^{\circledR}$ [22]. One of the studies primarily evaluating PRM also had an intervention arm evaluating intraperitoneal saline vs. nothing [15]. The results from this arm have been included in "other techniques".

Due to the heterogeneity of the included studies, it was not possible to convert the outcome measurements into dichotomous data or continuous data in order to demonstrate an overall effect. Therefore, no estimates of treatment effects or meta-analyses are presented in this systematic review. Instead, we preferred to indicate if a significant effect was demonstrated $(p<0.05)$. As it would have no direct consequences on the results presented here, we decided making an evaluation of risk of bias for the included studies.

\section{Intraperitoneal local anaesthetics}

Six RCTs evaluated the effect of intraperitoneal local anaesthetics [10-15]. The results are presented in Table 1. The administration method, location and type of intraperitoneal local anaesthetics varied between studies (Table 1). The severity of SP was assessed by using the visual analogue scale (VAS) in all studies [10-15]. One study assessed SP at rest using VAS and SP during coughing on a four-point scale [14]. Three studies reported VAS at rest and during coughing/mobilisation $[11,13,14]$. One study assessed VAS at rest [15]. The final two studies did not report the method of the VAS assessment [10, 12]. In one study, the control group received no intraperitoneal solution [13]. In the remaining five studies, the control group received saline solution $[10-12,14,15]$. None of the studies found a significant reduction in the incidence of SP [11-15]. Only two out of six studies found a significant reduction in SP severity $[10,14]$. One of these only found a significant reduction of SP severity during coughing in the first post-operative hour [14]. All studies reported post-operative analgesic consumption. A significant decrease in analgesic requirement was found in three out of six studies $[10,11,14]$.

Pulmonary recruitment manoeuvre

Three RCTs evaluated the effect of PRM [5, 8, 16]. The results are presented in Table 2. All studies reported both the 
Fig. 1 Flow diagram demonstrating the selection process of included studies

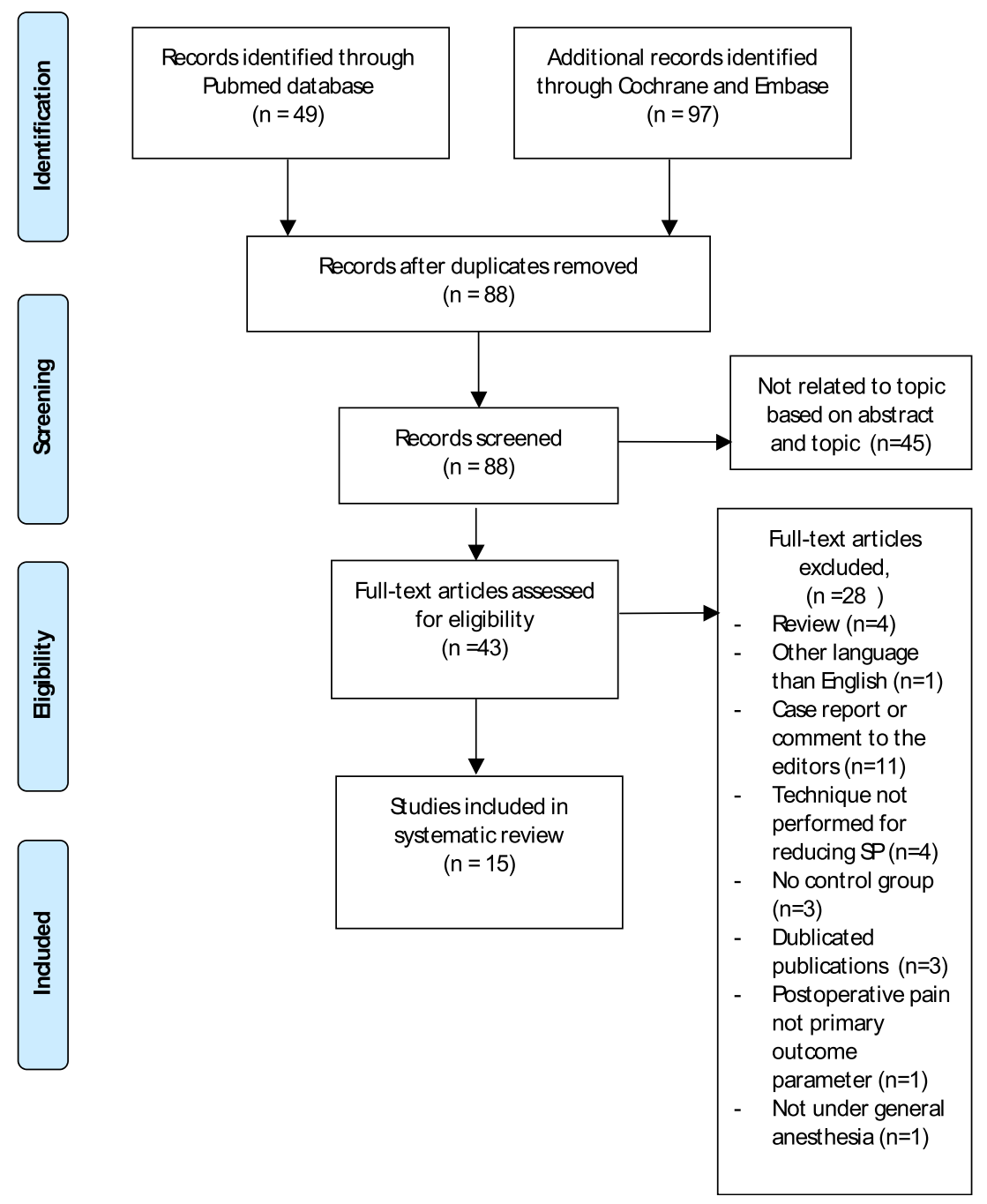

measured the severity of SP both at rest and during coughing [19]. The last two studies did not report whether the measurement was done at rest and/or during coughing/mobilisation [17, 18]. One study reported both the incidence and severity of SP [18] and found a significant reduction in both (severity at $24 \mathrm{~h}$ and $48 \mathrm{~h}$ post-operatively) [18]. The last two studies reported only the severity of SP and found a significant reduction compared with the control group (12-72 h post-operatively [17] and at 4 and $48 \mathrm{~h}$ postoperatively [19]). Two studies reported post-operative analgesic consumption, and both found a significant reduction in the post-operative analgesic requirements $[18,19]$.

\section{Other techniques}

The remaining three RCTs investigated the effect of gasless laparoscopy using Laprolift ${ }^{\circledR}$ [22], minilaparoscopy [21] and intraperitoneal saline [8]. The results are presented in Table 4. None of the studies reported on SP incidence. All studies reported the severity of SP using VAS. The only intervention that reduced the severity of SP was intraperitoneal saline 
administration [17]. One of the studies evaluating PRM also evaluated intraperitoneal saline in a separate arm and found a significant reduction in both the incidence and severity of SP [8]. This reduction was also found when intraperitoneal saline was compared to PRM [8].

\section{Discussion}

In this systematic review, PRM showed overall promising results in reducing both the incidence and severity of SP after laparoscopic surgery for benign gynaecological disease. Despite this, only one study found reduced postoperative analgesic requirement. Another promising technique was drainage, although this alternative raises concerns regarding complications. The use of intraperitoneal local anaesthetics had limited effect on the incidence and severity of SP. Intraperitoneal saline on the other hand had an effect, but the evidence is limited to two studies.

Several causes of SP after laparoscopic surgery have been reported in the literature, but the leading hypothesis is based on carbon dioxide $\left(\mathrm{CO}_{2}\right)$ in the abdominal cavity. It is thought that pneumoperitoneum causes diaphragmatic irritation by overstretching the diaphragmatic muscle fibres resulting in a pain sensation mediated by the phrenic nerve [23]. Jackson et al. investigated the association between the dimension of the gas bubbles in the peritoneal cavity and the severity of pain and found a correlation between the residual gas volume and post-laparoscopic pain [23]. To support the theory of overstretched diaphragmatic muscle fibres, it has also been shown that low insufflation rate reduces post-operative SP [24]. Rapid distension is associated with tearing of blood vessels, traumatic traction of the nerves and release of inflammatory mediators [6] leading to post-operative pain.

Intraperitoneal administration of local anaesthetics has been evaluated for several different laparoscopic procedures [25-29]. It is based on the theory that the instillation of local anaesthetics in the peritoneal cavity blocks the visceral afferent signalling, thereby resulting in reduced nociception [30]. The literature presented in this review does not support the use of local anaesthetics for SP reduction in benign gynaecological laparoscopy. None of the studies could demonstrate a reduction in incidence, and only two out of six studies reported a significant reduction in the severity of SP $[10,14]$. Despite this, three out of six studies found a significant reduction of post-operative analgesic consumption $[10,11,14]$. The present evidence does not support a widespread use of intraperitoneal local anaesthetics in benign gynaecological laparoscopy for reduction of SP. Besides a local effect in the peritoneal cavity, the analgesic effect of intraperitoneal local anaesthetics could also be mediated through systemic absorption. There are measurable plasma levels of local anaesthetics shortly after 
Table 2 The effect of pulmonary recruitment manoeuvre (PRM) on the incidence and severity of shoulder pain (SP)

\begin{tabular}{|c|c|c|c|c|c|c|c|}
\hline Reference & $\begin{array}{l}\text { Publication } \\
\text { year }\end{array}$ & Number & Procedure & Intervention & $\begin{array}{l}\text { Incidence } \\
\text { of SP }\end{array}$ & $\begin{array}{l}\text { Severity } \\
\text { of SP }\end{array}$ & $\begin{array}{l}\text { Post-operative } \\
\text { analgesics }\end{array}$ \\
\hline Phelps et al. [5] & 2008 & $100,46 / 54$ & $\begin{array}{l}\text { Elective outpatient gynaecologic } \\
\text { surgery }\end{array}$ & PRM vs. nothing & $\downarrow$ & - & $\mathrm{N} / \mathrm{A}$ \\
\hline Sharami et al. [16] & 2010 & $131,67 / 64$ & $\begin{array}{l}\text { Minor laparoscopic gynaecologic } \\
\text { surgery }\end{array}$ & PRM vs. nothing & $\downarrow$ & $\downarrow$ & $\downarrow$ \\
\hline Tsai et al. [8] & 2011 & $104,53 / 51$ & $\begin{array}{l}\text { Laparoscopic surgery for benign } \\
\text { gynaecologic lesions }\end{array}$ & PRM vs. nothing & $\downarrow$ & $\downarrow$ & - \\
\hline Tsai et al. [8] & 2011 & $107,53 / 54$ & $\begin{array}{l}\text { Laparoscopic surgery for benign } \\
\text { gynaecologic lesions }\end{array}$ & PRM vs. INSI & $\uparrow$ & $\uparrow$ & - \\
\hline
\end{tabular}

$N / A$ not available, $\downarrow$ significant decrease, $\uparrow$ significant increase, - not significant

intraperitoneal administration due to absorption over the peritoneal surface. A potential risk with administration of intraperitoneal local anaesthetics is that the dosage is difficult to control. Although plasma levels of local anaesthetics have been reported to be close to and above safe threshold, no clinical toxicity or adverse effects have thus far been reported [31]. It cannot be ruled out that local anaesthetics can be used to reduce SP after laparoscopic surgery for benign gynaecological disease, but further studies are warranted before a general recommendation can be made.

The most promising data were found in the studies evaluating the effect of PRM. PRM was associated with an overall reduction in both the incidence and the severity of SP $[5,8$, 16]. PRM works by removing residual $\mathrm{CO}_{2}$ from the peritoneal cavity by manually delivering pulmonary inflations with a pressure of between 40 and $60 \mathrm{cmH}_{2} 0$. The positive pressure causes the lungs to expand and the diaphragm to descend, resulting in the evacuation of residual $\mathrm{CO}_{2}$ from the peritoneal cavity $[5,8,16]$. There is heterogeneity concerning the maximal pressure used during inflation. One study applied a pressure of $60 \mathrm{cmH}_{2} 0$ [5]. Although there are concerns that this ventilation pressure can result in pneumothorax, the authors did not report any cardiovascular or pulmonary complications. Another study applied the PRM technique with a reduced pressure $\left(40 \mathrm{cmH}_{2} \mathrm{O}\right)$ and also found a significant reduction in the incidence and severity of SP without cardiovascular or pulmonary complications [16]. Thus, it seems that a significant reduction in SP can be achieved with lower pressures, thus minimising the potential risk of complications. One of the studies which applied the PRM technique also compared PRM to intraperitoneal saline. This study arm reported a reduction in both the incidence and severity of SP when saline was compared to PRM. The authors hypothesised that this reduction is due to a longer lasting effect of intraperitoneal saline compared to PRM. A possible explanation of this longer lasting effect is that intraperitoneal saline acts as a buffer system. The $\mathrm{CO}_{2}$ in the abdominal cavity resolves in the water and becomes carbonic acid. From here, the carbonic acid is transformed to bicarbonate through the red blood cell in the intravascular space. In the lungs, the bicarbonate is again transformed to $\mathrm{CO}_{2}$ which is exhaled by the patient [8].

Intraperitoneal drainage was also associated with a reduction in both the incidence and severity of SP [17-19]. The application of a drain to reduce SP is based on the assumption that it allows residual $\mathrm{CO}_{2}$ to be removed from the abdominal cavity. Open and closed suction drainage was associated with a reduction in the severity $[17,18]$ and incidence of SP $[18$, 19]. In two of the three RCTs, there was also a reduction in the post-operative analgesic requirements [18, 19]. However, it can be discussed if it is a cost-effective and safe procedure [19]. Although there were no complications reported in any of the studies [17-19], the use of drains can potentially lead to complications such as wound infections, increased abdominal wall pain, decreased pulmonary function, restricted mobilisation and prolonged hospital stay [32]. With the application of PRM, which is also based on removing residual $\mathrm{CO}_{2}$

Table 3 The effect of drainage on the incidence and severity of shoulder pain (SP)

\begin{tabular}{|c|c|c|c|c|c|c|c|}
\hline Reference & $\begin{array}{l}\text { Publication } \\
\text { year }\end{array}$ & Number & Procedure & Intervention & $\begin{array}{l}\text { Incidence } \\
\text { of SP }\end{array}$ & $\begin{array}{l}\text { Severity } \\
\text { of SP }\end{array}$ & $\begin{array}{l}\text { Post-operative } \\
\text { analgesics }\end{array}$ \\
\hline Swift et al. [17] & 2002 & $67,30 / 37$ & $\begin{array}{l}\text { Laparoscopic gynaecologic } \\
\text { surgery for benign disease }\end{array}$ & $\begin{array}{l}\text { Open drain } 4 \mathrm{~h} \\
\text { post-operatively }\end{array}$ & N/A & $\downarrow$ & N/A \\
\hline Abbott et al. [19] & 2001 & $161,82 / 79$ & $\begin{array}{l}\text { Diagnostic/minor gynaecologic } \\
\text { laparoscopy }\end{array}$ & $\begin{array}{l}\text { Open drain } 4 \mathrm{~h} \\
\text { post-operatively }\end{array}$ & $\mathrm{N} / \mathrm{A}$ & $\downarrow$ & $\downarrow$ \\
\hline Shen et al. [18] & 2003 & $164,80 / 84$ & $\begin{array}{l}\text { Laparoscopic assisted vaginal } \\
\text { hysterectomy }\end{array}$ & Closed suction drainage & $\downarrow$ & $\downarrow$ & $\downarrow$ \\
\hline
\end{tabular}

$N / A$ not available, $\downarrow$ significant decrease 
Table 4 The effect other interventions on the incidence and severity of shoulder pain (SP)

\begin{tabular}{|c|c|c|c|c|c|c|c|}
\hline Reference & $\begin{array}{l}\text { Publication } \\
\text { year }\end{array}$ & Number & Procedure & Intervention & $\begin{array}{l}\text { Incidence } \\
\text { of SP }\end{array}$ & $\begin{array}{l}\text { Severity } \\
\text { of SP }\end{array}$ & $\begin{array}{l}\text { Post-operative } \\
\text { analgesics }\end{array}$ \\
\hline Guido et al. [22] & 1998 & $54,30 / 24$ & Laparoscopic tubal ligation & $\begin{array}{l}\text { Gasless laparoscopy with } \\
\text { Laprolift } \AA\end{array}$ & $\mathrm{N} / \mathrm{A}$ & - & N/A \\
\hline Ghezzi et al. [21] & 2011 & $76,38 / 38$ & Hysterectomy & $\begin{array}{l}\text { Minilaparoscopic vs. } \\
\text { conventional hysterectomy }\end{array}$ & N/A & - & - \\
\hline Tsai et al. [8] & 2011 & $106,54 / 51$ & $\begin{array}{l}\text { Laparoscopic surgery for } \\
\text { benign gynaecologic lesions }\end{array}$ & Saline instillation & $\downarrow$ & $\downarrow$ & - \\
\hline Suginami et al. [20] & 2009 & $40,21 / 19$ & $\begin{array}{l}\text { Laparoscopic gynaecologic } \\
\text { surgery }\end{array}$ & Saline instillation & N/A & $\downarrow$ & - \\
\hline
\end{tabular}

$N / A$ not available, $\downarrow$ significant decrease, - not significant

from the abdominal cavity, none of these complications exist. In addition, the PRM technique can be performed in a much shorter time duration compared to drainage and allows for faster mobilisation. Thus, it seems that for removing residual $\mathrm{CO}_{2}$, the PRM technique is favourable compared to drainage with respect to ease of implementation and potential postoperative complications.

Another technique that is also based on removing residual $\mathrm{CO}_{2}$ from the abdominal cavity is intraperitoneal saline instillation. Intraperitoneal saline instillation is believed to reduce SP by two different mechanisms of action. First, it increases the intraperitoneal pressure which displaces the residual carbon dioxide from the peritoneal cavity. Secondly, it acts as a physiological buffer whereby the residual carbon dioxide is dissolved [8, 20]. Both RCTs evaluating this technique found a significant reduction in the severity of $\mathrm{SP}$, and Tsai et al. also found a significant reduction in the incidence of SP. In this study, they even found that saline instillation was more effective than the PRM technique [8]. In this systematic review, all studies, except one evaluating local anaesthetics, used a placebo group with intraperitoneal saline. The fact that saline does seem to reduce SP could account for the discouraging results found in the studies comparing local anaesthetics vs. saline. In our opinion, future studies evaluating local anaesthetics should primarily compare it to a control group using no instillation. The painreducing effect of saline may be due to the buffer system described above as well as to the displacement of trapped $\mathrm{CO}_{2}$ from the peritoneal cavity at the end of surgery.

Gasless laparoscopy performed with Laprolift ${ }^{\circledR}$ is an alternative surgical technique to conventional laparoscopy with pneumoperitoneum. The technique eliminates the effect of residual $\mathrm{CO}_{2}$ in the peritoneal cavity completely. Despite this, no reduction in SP severity could be found in this study [22]. The occurrence of SP without pneumoperitoneum indicates that the pathogenesis of SP is complex and multifactorial. This technique is particularly indicated in elderly patients with pulmonary/cardiac comorbidities, where increased abdominal pressure and the use of $\mathrm{CO}_{2}$ can have potential side effects.
The last study aimed to reduce post-operative pain by minimising the surgical trauma. This study compared the effect of minilaparoscopy vs. conventional laparoscopic hysterectomy and did not report a significant difference in the severity of SP. Keeping in mind the hypnotised pathogeneses for SP, this technique should have a little impact on SP as the only difference between the two techniques is the port sizes (port size of 3 vs. $5 \mathrm{~mm}$ ) [21].

There are several limitations to this systematic review. Due to the heterogeneity of the included studies, it is difficult to compare them and impossible to perform a metaanalyses. Another limitation is the quality. Outcome parameters were often not clearly defined. Evaluation of sample size and power calculation was not performed in all the included studies. Most RCTs included in this review did not describe in detail how they assessed pain (during rest/coughing/mobilisation) neither did they describe the timing of VAS measurements. Description of the inclusion and exclusion criteria were not well defined or not reported at all. Another point of limitation is that some studies did not report the indication for laparoscopic surgery. Finally, this systematic review used language restriction. Only studies written in English were included. This may introduce language bias and lead to erroneous conclusions.

Several different techniques to reduce SP have been evaluated in the literature. A definite conclusion is difficult based on the retrieved evidence presented. This was due to the heterogeneity of the included studies, the study size and the quality of included studies. Overall the pulmonary recruitment manoeuvre and drainage show promising results in reducing both the incidence and severity of SP. In an era of fast-track surgery with early mobilisation, the routine use of drainage is not recommended and only increases the risk of postoperative complications. Another promising method is intraperitoneal saline, although the evidence is too weak to make any definite conclusions. The results presented in this review do not support the use of intraperitoneal local anaesthetics.

Other hypothesis of reducing peritoneal damage during laparoscopic surgery is to keep the peritoneal surface moist 
by changing the condition of the gas for pneumoperitoneum. Applying $\mathrm{CO}_{2}$ at body temperature and humidified condition is close to the homeostatic condition of the peritoneal cavity which is thought to be more physiologic and less damaging to the peritoneal cavity. Future studies need to elucidate this hypothesis [33].

In conclusion, based on the findings in this review, PRM using a pressure of $40 \mathrm{cmH}_{2} \mathrm{O}$ can be recommended as a simple and cost-effective method to reduce SP after laparoscopy for benign gynaecological disease. However, it is not possible to make a definite conclusion concerning the clinical effects and larger well-designed trials are needed to investigate the most appropriate technique.

\section{References}

1. Yuen PM, Mak TW, Yim SF, Ngan Kee WD, Lam CW, Rogers MS et al (1998) Metabolic and inflammatory responses after laparoscopic and abdominal hysterectomy. Am J Obstet Gynecol 1:1-5

2. Ferrari MM, Berlanda N, Mezzopane R, Ragusa G, Cavallo M, Pardi G (2000) Identifying the indications for laparoscopically assisted vaginal hysterectomy: a prospective, randomised comparison with abdominal hysterectomy in patients with symptomatic uterine fibroids. BJOG 5:620-625

3. Olsson JH, Ellstrom M, Hahlin M (1996) A randomised prospective trial comparing laparoscopic and abdominal hysterectomy. $\mathrm{Br}$ J Obstet Gynaecol 4:345-350

4. Bijen CB, Vermeulen KM, Mourits MJ, de Bock GH (2009) Costs and effects of abdominal versus laparoscopic hysterectomy: systematic review of controlled trials. PLoS One 10:e7340

5. Phelps P, Cakmakkaya OS, Apfel CC, Radke OC (2008) A simple clinical maneuver to reduce laparoscopy-induced shoulder pain: a randomized controlled trial. Obstet Gynecol 1115:1155-1160

6. Alexander JI (1997) Pain after laparoscopy. Br J Anaesth 3:369-378

7. Dobbs FF, Kumar V, Alexander JI, Hull MG (1987) Pain after laparoscopy related to posture and ring versus clip sterilization. $\mathrm{Br}$ J Obstet Gynaecol 3:262-266

8. Tsai HW, Chen YJ, Ho CM, Hseu SS, Chao KC, Tsai SK et al (2011) Maneuvers to decrease laparoscopy-induced shoulder and upper abdominal pain: a randomized controlled study. Arch Surg 12:1360-1366

9. Dixon JB, Reuben Y, Halket C, O'Brien PE (2005) Shoulder pain is a common problem following laparoscopic adjustable gastric band surgery. Obes Surg 8:1111-1117

10. Benhamou D, Narchi P, Mazoit JX, Fernandez H (1994) Postoperative pain after local anesthetics for laparoscopic sterilization. Obstet Gynecol 5:877-880

11. Callesen T, Hjort D, Mogensen T, Schouenborg L, Nielsen D, Reventlid H et al (1999) Combined field block and i.p. instillation of ropivacaine for pain management after laparoscopic sterilization. Br J Anaesth 4:586-590

12. Johnson N, Onwude JL, Player J, Hicks N, Yates A, Bryce F et al (1994) Pain after laparoscopy: an observational study and a randomized trial of local anesthetic. J Gynecol Surg 3:129-138

13. Kaufman Y, Hirsch I, Ostrovsky L, Klein O, Shnaider I, Khoury E et al (2008) Pain relief by continuous intraperitoneal nebulization of ropivacaine during gynecologic laparoscopic surgery-a randomized study and review of the literature. J Minim Invasive Gynecol 5:554-558
14. Ozer Y, Tanriverdi HA, Ozkocak I, Altunkaya H, Demirel CB, Bayar U et al (2005) Evaluation of a local anaesthesia regimen using a subphrenic catheter after gynaecological laparoscopy. Eur J Anaesthesiol 6:442-446

15. Chou YJ, Ou YC, Lan KC, Jawan B, Chang SY, Kung FT (2005) Preemptive analgesia installation during gynecologic laparoscopy: a randomized trial. J Minim Invasive Gynecol 4:330-335

16. Sharami SH, Sharami MB, Abdollahzadeh M, Keyvan A (2011) Randomized clinical trial of the influence of pulmonary recruitment maneuver on reducing shoulder pain after laparoscopy. Eur J Pain Suppl 1:36

17. Swift G, Healey M, Varol N, Maher P, Hill D (2002) A prospective randomised double-blind placebo controlled trial to assess whether gas drains reduce shoulder pain following gynaecological laparoscopy. Aust N Z J Obstet Gynaecol 3:267-270

18. Shen CC, Wu MP, Lu CH, Kung FT, Huang FJ, Huang EY et al (2003) Effects of closed suction drainage in reducing pain after laparoscopic-assisted vaginal hysterectomy. J Am Assoc Gynecol Laparosc 2:210-214

19. Abbott J, Hawe J, Srivastava P, Hunter D, Garry R (2001) Intraperitoneal gas drain to reduce pain after laparoscopy: randomized masked trial. Obstet Gynecol 1:97-100

20. Suginami R, Taniguchi F, Suginami H (2009) Prevention of postlaparoscopic shoulder pain by forced evacuation of residual CO(2). JSLS 1:56-59

21. Ghezzi F, Cromi A, Siesto G, Uccella S, Boni L, Serati M et al (2011) Minilaparoscopic versus conventional laparoscopic hysterectomy: results of a randomized trial. J Minim Invasive Gynecol 4:455-461

22. Guido RS, Brooks K, McKenzie R, Gruss J, Krohn MA (1998) A randomized, prospective comparison of pain after gasless laparoscopy and traditional laparoscopy. J Am Assoc Gynecol Laparosc 2:149-153

23. Jackson SA, Laurence AS, Hill JC (1996) Does post-laparoscopy pain relate to residual carbon dioxide? Anaesthesia 5:485-487

24. Berberoglu M, Dilek ON, Ercan F, Kati I, Ozmen M (1998) The effect of $\mathrm{CO}_{2}$ insufflation rate on the postlaparoscopic shoulder pain. J Laparoendosc Adv Surg Tech A 5:273-277

25. Lepner U, Goroshina J, Samarutel J (2003) Postoperative pain relief after laparoscopic cholecystectomy: a randomised prospective double-blind clinical trial. Scand J Surg 2:121-124

26. Kang H, Kim BG (2010) Intraperitoneal ropivacaine for effective pain relief after laparoscopic appendectomy: a prospective, randomized, double-blind, placebo-controlled study. J Int Med Res 3:821-832

27. Park YH, Kang H, Woo YC, Park SG, Baek CW, Jung YH et al (2011) The effect of intraperitoneal ropivacaine on pain after laparoscopic colectomy: a prospective randomized controlled trial. J Surg Res 1:94-100

28. Sherwinter DA, Ghaznavi AM, Spinner D, Savel RH, Macura JM, Adler H (2008) Continuous infusion of intraperitoneal bupivacaine after laparoscopic surgery: a randomized controlled trial. Obes Surg 12:1581-1586

29. Goldstein A, Grimault P, Henique A, Keller M, Fortin A, Darai E (2000) Preventing postoperative pain by local anesthetic instillation after laparoscopic gynecologic surgery: a placebo-controlled comparison of bupivacaine and ropivacaine. Anesth Analg 2:403-407

30. Kahokehr A, Sammour T, Srinivasa S, Hill AG (2010) Systematic review and meta-analysis of intraperitoneal local anaesthetic for pain reduction after laparoscopic gastric procedures. Br J Surg 1:29-36

31. Kahokehr A, Sammour T, Vather R, Taylor M, Stapelberg F, Hill AG (2010) Systemic levels of local anaesthetic after intra-peritoneal application - a systematic review. Anaesth Intensive Care 4:623-638

32. Uchiyama K, Tani M, Kawai M, Terasawa H, Hama T, Yamaue H (2007) Clinical significance of drainage tube insertion in laparoscopic cholecystectomy: a prospective randomized controlled trial. J Hepatobiliary Pancreat Surg 6:551-556

33. Ott DE (2004) The peritoneum and the pneumoperitoneum: a review to improve clinical outcome. Gynecol Surg 1:101-106 